\title{
Mid-Infrared Raman Sources Using Spontaneous Raman Scattering in Germanium Core Optical Fibers
}

\author{
Pengfei Wang \\ Technological University Dublin, pengfei.wang@tudublin.ie \\ Christy Charlton O'Mahony \\ Dublin City University \\ Timothy Lee \\ University of Southampton
}

See next page for additional authors

Follow this and additional works at: https://arrow.tudublin.ie/engscheceart

Part of the Engineering Commons

\section{Recommended Citation}

Wang, P. et al (2013) Mid-Infrared Raman Sources Using Spontaneous Raman Scattering in Germanium Core Optical Fibers. Applied Physics Letters, 102, 011111; doi:10.1063/1.4773884

This Article is brought to you for free and open access by the School of Electrical and Electronic Engineering at ARROW@TU Dublin. It has been accepted for inclusion in Articles by an authorized administrator of ARROW@TU Dublin. For more information, please contact arrow.admin@tudublin.ie, aisling.coyne@tudublin.ie, gerard.connolly@tudublin.ie.

Funder: Irish Research Council, Eu Marie-Curie Actions under FP7, Science Foundation Ireland, Royal Society Londong 


\section{Authors}

Pengfei Wang, Christy Charlton O'Mahony, Timothy Lee, Rand Ismaeel, Thomas Hawkins, Yuliya

Semenova, Lin Bo, Qiang wu, Colette McDonagh, Gerald Farrell, John Ballato, and Gilberto Brambilla 


\section{AIP Applese Physics \\ Letters}

\section{Mid-infrared Raman sources using spontaneous Raman scattering in germanium core optical fibers}

Pengfei Wang, Christy Charlton O'Mahony, Timothy Lee, Rand Ismaeel, Thomas Hawkins et al.

Citation: Appl. Phys. Lett. 102, 011111 (2013); doi: 10.1063/1.4773884

View online: http://dx.doi.org/10.1063/1.4773884

View Table of Contents: http://apl.aip.org/resource/1/APPLAB/v102/i1

Published by the American Institute of Physics.

\section{Related Articles}

Restoring transmission of irradiated image fiber bundles

Rev. Sci. Instrum. 83, 10E514 (2012)

A magnifying fiber element with an array of sub-wavelength Ge/ZnSe pixel waveguides for infrared imaging Appl. Phys. Lett. 101, 021108 (2012)

Embedded calibration system for the DIII-D Langmuir probe analog fiber optic links

Rev. Sci. Instrum. 83, 10D710 (2012)

Analytical analysis of modulation instability in fiber optics

AIP Advances 2, 022168 (2012)

Atmospheric pressure dielectric barrier microplasmas inside hollow-core optical fibers

J. Appl. Phys. 111, 073304 (2012)

\section{Additional information on Appl. Phys. Lett.}

Journal Homepage: http://apl.aip.org/

Journal Information: http://apl.aip.org/about/about_the_journal

Top downloads: http://apl.aip.org/features/most_downloaded

Information for Authors: http://apl.aip.org/authors

\section{ADVERTISEMENT}

\section{AIP Applied Physics Letters}

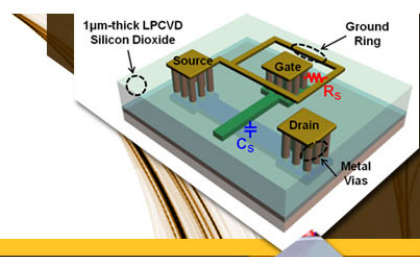

\section{SURFACES AND} INTERFACES

Focusing on physical, chemical, biological structural, optical, magnetic and electrical properties of surfaces and interfaces, and more..

\section{EXPLORE WHAT'S NEW IN APL}

SUBMIT YOUR PAPER NOW!
ENERCY CONVERSION AND STORACE 


\title{
Mid-infrared Raman sources using spontaneous Raman scattering in germanium core optical fibers
}

\author{
Pengfei Wang, ${ }^{1,2, a)}$ Christy Charlton O'Mahony, ${ }^{3}$ Timothy Lee, ${ }^{1}$ Rand Ismaeel, ${ }^{1}$ \\ Thomas Hawkins, ${ }^{4}$ Yuliya Semenova,${ }^{2}$ Lin Bo, ${ }^{2}$ Qiang Wu, ${ }^{2}$ Colette McDonagh, ${ }^{3}$ \\ Gerald Farrell, ${ }^{2}$ John Ballato, ${ }^{4}$ and Gilberto Brambilla ${ }^{1}$ \\ ${ }^{1}$ Optoelectronics Research Centre, University of Southampton, Southampton SO17 1BJ, United Kingdom \\ ${ }^{2}$ Photonics Research Centre, Dublin Institute of Technology, Kevin Street, Dublin 8, Ireland \\ ${ }^{3}$ Biomedical Diagnostics Institute, School of Physical Sciences, Dublin City University, Glasnevin, \\ Dublin 9, Ireland \\ ${ }^{4}$ Center for Optical Materials Science and Engineering Technologies (COMSET), Clemson University, \\ Clemson, South Carolina 29634, USA
}

(Received 14 September 2012; accepted 17 December 2012; published online 7 January 2013)

\begin{abstract}
Mid-infrared Raman sources based on spontaneous Raman scattering have been demonstrated in a $15-\mu \mathrm{m}$ diameter glass-clad crystalline germanium optical fiber and in a germanium-wire. A quantum cascade laser was used as pump at a wavelength of $5.62 \mu \mathrm{m}$. Because of their ultra-high optical nonlinearities and extremely broad transparency window, germanium core fibers offer the possibility of fabricating compact and efficient mid-infrared sources. (C) 2013 American Institute of Physics. [http://dx.doi.org/10.1063/1.4773884]
\end{abstract}

Interest in mid-infrared (IR) light sources has increased in recent years due to their many applications in security, sensing, and the pumping of lasers at even longer wavelengths (terahertz). The most widespread and inexpensive mid-IR sources are thermal emitters, which however suffer from incoherent and low brightness outputs. Indeed, their emissions cannot exceed the radiation power of an ideal black body emitter. While they are suitable for gas detection, they are inappropriate for long-range light detection and ranging (LIDAR), heterodyne measurements, or optical pumping of longer wavelength solid-state lasers, which also require high brightness. Quantum cascade lasers (QCLs) were demonstrated in 1994 (Ref. 1) and are the most promising electrically pumped semiconductor lasers for mid- and far-IR light generation. While QCLs can generate narrowband and high quality continuous wave (CW) and pulsed beams, they are narrowband, relatively inefficient, ${ }^{2,3}$ often require low temperature operation, and are available only at selected wavelengths. Active fibers have been proposed as a means to achieve efficient lasing in the mid-IR, but to date, such fibers rely on compound glasses, such as chalcogenides, ${ }^{4}$ which are transparent in the mid-IR but are not easily available and generally mechanically fragile. Finally parametric processes, ${ }^{5}$ for example, in an optical parametric oscillator, have been widely used, but these require a nonlinear medium (usually crystals) and multiple high peak power pumps.

There is thus a need to develop efficient high brightness sources at long wavelengths, without the disadvantages associated with existing sources. In this letter, Raman scattering is exploited in order to generate light in the mid-infrared region (at $\lambda>6 \mu \mathrm{m}$ ) using a germanium wire and a glassclad germanium core optical fiber.

Germanium $(\mathrm{Ge})$ has a large $n_{2}$ nonlinearity $\left(\sim 10^{3}\right.$ times that of silica ${ }^{6,7}$, a high optical damage threshold compared

\footnotetext{
${ }^{\text {a) }}$ Author to whom correspondence should be addressed. Electronic mail: pw3y09@orc.soton.ac.uk.
}

with traditional nonlinear glasses, ${ }^{8}$ and, most importantly, an extremely broad transparency window that extends from the near-infrared well into the mid-infrared $(\lambda=2-20 \mu \mathrm{m})$ spectral regions. ${ }^{9}$ Ge-based passive optical components such as mirrors and lenses have found numerous applications in IR imaging systems operating in the atmospheric windows (both $3-5$ and $8-13 \mu \mathrm{m}$ ), where natural greenhouse gases do not exhibit strong absorption. Some active components have been demonstrated in the near-IR wavelengths such as an electrically pumped Ge laser operating between $1520 \mathrm{~nm}$ and $1700 \mathrm{~nm}$ (Ref. 10) and resonance modes observed over the range of $1500-1675 \mathrm{~nm}$ from a resonator fabricated by integrating a Ge light emitting diode with a microdisk cavity. ${ }^{11}$ However, Ge in the near-IR has strong absorption, which reduces propagation length and conversion efficiency in nonlinear processes. On the other hand, for $\lambda>1.9 \mu \mathrm{m}$, Ge absorption becomes negligible for propagation lengths of the order of centimeters and, for example, whispering gallery modes have recently been observed around $\lambda \sim 2 \mu \mathrm{m} .{ }^{12}$ Twophoton absorption also becomes negligible at $\lambda>4 \mu \mathrm{m}$. In the past, Raman scattering has been used to characterize semiconductor materials ${ }^{13}$ and, recently, to generate the wavelengths in the near-IR region. ${ }^{10,14}$ Here, we exploit Raman scattering to generate high output power fiber-based sources in the mid-IR.

The fiber sample employed here was manufactured at Clemson University (Clemson, USA) and has a crystalline Ge core and an amorphous borosilicate cladding with diameters of $15 \mu \mathrm{m}$ (core) and $150 \mu \mathrm{m}$ (total fiber diameter), respectively. ${ }^{15}$ A microscope image of the fiber is shown in Fig. 1(a). The fiber had a refractive index difference of $\Delta \mathrm{n}=2.5$ and supported multimode operation in the wavelength range $\lambda<10 \mu \mathrm{m}$. Figs. 1(b) and 1(c) present simulated $\mathrm{HE}_{11}$ modal intensity profiles at the pump and at the borosilicate Raman scattering wavelengths, respectively. When light is launched into the fundamental mode, most of the intensity is confined to the core. The fraction of power, $\eta$, propagating 
(a)

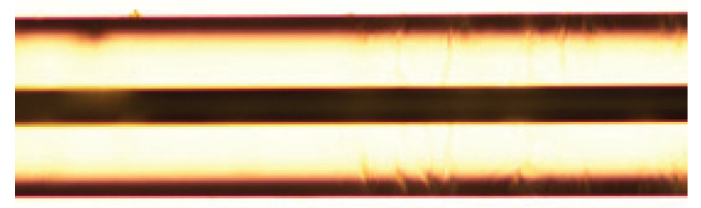

(b) $\lambda=5.62 \mu \mathrm{m}$

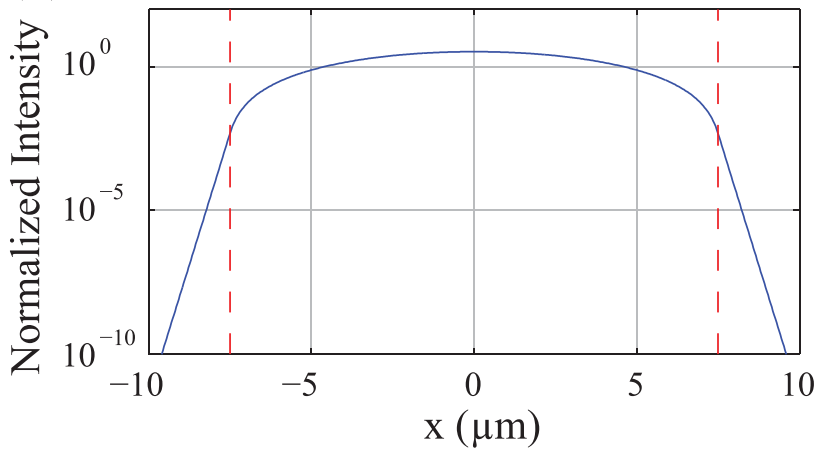

(c) $\lambda=7.60 \mu \mathrm{m}$

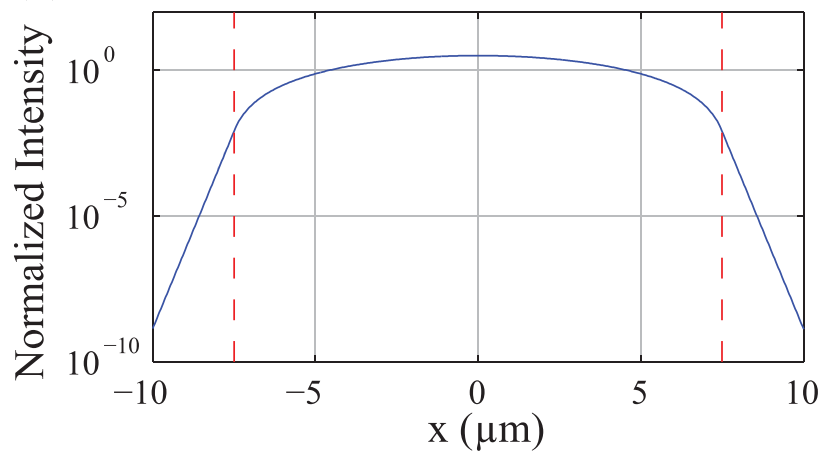

FIG. 1. (a) Optical micrograph of the glass-clad crystalline Ge core fiber and intensity profiles of the fundamental $\mathrm{HE}_{11}$ mode at (b) $\lambda=5.62 \mu \mathrm{m}$ and (c) $\lambda=7.6 \mu \mathrm{m}$.

in the core was calculated to be $\eta=0.999905$ at $\lambda=5.62 \mu \mathrm{m}$ and $\eta=0.999774$ at $\lambda=7.60 \mu \mathrm{m}$, calculated from the Poynting vector $S$ using the equation of $\eta=\int_{\text {core }} S d A / \int_{-\infty}^{\infty} S d A$.

Fig. 2 shows the optical set-up employed. A distributed feedback (DFB) QCL (Alpes Lasers, Neuchatel, Switzerland) system equipped with a temperature controller (Alpes Lasers, TC-51), modulated by a QCL pulse switching and timing module (Alpes Lasers, TPG 128), was operated at a temperature of $12^{\circ} \mathrm{C}$ and modulated at a pulse duration up to $10 \mathrm{~ns}$ with a period of $2.5 \mu \mathrm{s}$. The pulse amplitude was controlled by an external power supply set up to $16.5 \mathrm{~V}$. Light at $\lambda \sim 5.62 \mu \mathrm{m}$ was launched from the QCL into the Ge fiber with a length of $4 \mathrm{~mm}$ via a collimator, an infrared polarizer, and a $\mathrm{ZnSe}$ lens. Light emitted from the distant end of the

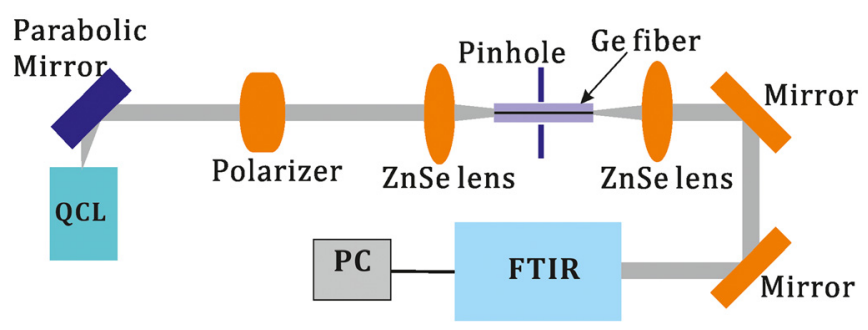

FIG. 2. Diagram of the experimental set-up for Raman scattering measurements.
Ge fiber was collected by a Fourier transform infrared spectrometer (FTIR, Thermo Fisher Scientific, USA) connected to a personal computer (PC).

Fig. 3 shows the Raman spectrum collected at the Ge fiber output. In analyzing the Raman spectroscopy, two major features can be identified at about 300 and 400$600 \mathrm{~cm}^{-1}$. The Raman peak located at $\sim 300 \mathrm{~cm}^{-1}$ can be attributed to crystalline Ge. ${ }^{13}$ The broader peak at longer wavenumbers $\left(400-800 \mathrm{~cm}^{-1}\right)$ can be attributed to the borosilicate cladding. ${ }^{16}$ The bands at $600-800 \mathrm{~cm}^{-1}$ are due to stretching vibrations of terminal groups of silicon-oxygen tetrahedrons with a different ratio of bridging and nonbridging oxygen atoms, while the $530-570 \mathrm{~cm}^{-1}$ band in the low-wavenumber region, which is the dominant feature in borosilicate glasses, is primarily due to symmetrical stretching and to a lesser extent to deformation vibrations of $\mathrm{Si}-\mathrm{O}-\mathrm{Si}$ bridges. Although a peak around $520 \mathrm{~cm}^{-1}$ might indicate that crystalline silicon could have separated during the fabrication of the Ge-core fiber at a high temperature, the recorded spectrum has a broader feature, consistent with a borosilicate glass. ${ }^{16}$ The broadening and asymmetry of the narrow Raman peaks, when compared to the reference spectra presented in Ref. 16, can be attributed to the relatively low resolution $\left(\sim 3 \mathrm{~cm}^{-1}\right)$ of the instrument used and possibly to the known polycrystallinity of Ge in the core of the optical fiber.

In order to verify that the Raman scattering in the region $400-1000 \mathrm{~cm}^{-1}$ is indeed due to the borosilicate cladding, the Ge-core/borosilicate-glass-cladding fiber was immersed in a $48 \%$ hydrofluoric acid (HF) for $7 \mathrm{~min}$ to remove the cladding and then rinsed in deionized water to remove any residual HF. As shown in the inset of Fig. 4, the etching process provides a Ge wire with a $15 \mu \mathrm{m}$ diameter. Fig. 4 also shows the Raman spectrum collected from the Ge wire output for an average input power from the QCL of $\sim 8 \mathrm{~mW}$; only the typical Ge Raman shift at $\sim 300 \mathrm{~cm}^{-1}$ is observed, in contrast to the broadband nature of Fig. 3, confirming that the Raman scattering in the region $400-1000 \mathrm{~cm}^{-1}$ in the fiber is due to the borosilicate cladding.

Fig. 5 shows the Raman signal for a low and a high average powers of $\sim 20 \mu \mathrm{W}$ and $8 \mathrm{~mW}$, respectively, from the Ge

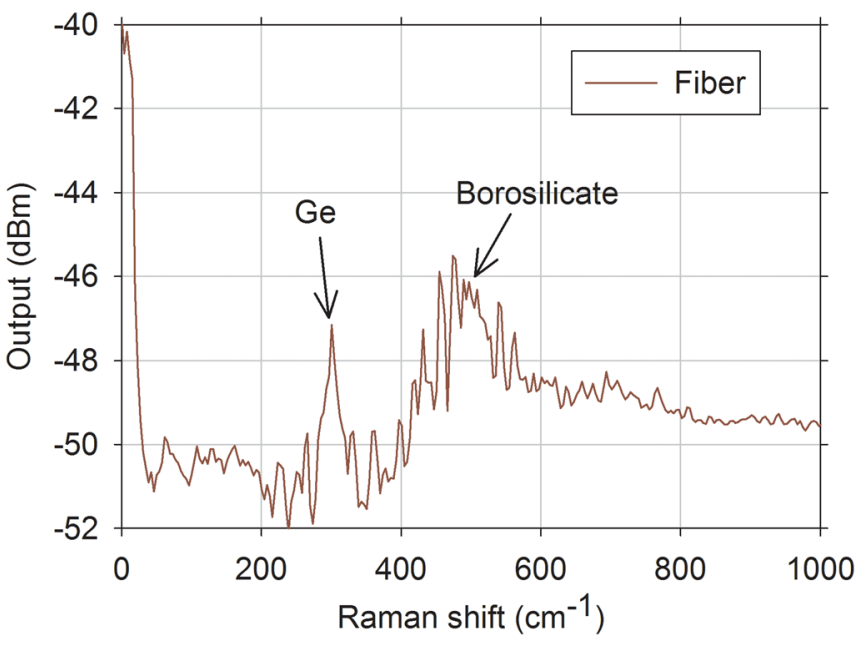

FIG. 3. Raman spectrum of Ge fiber recorded with $20 \mu \mathrm{W}$ average pump power. 


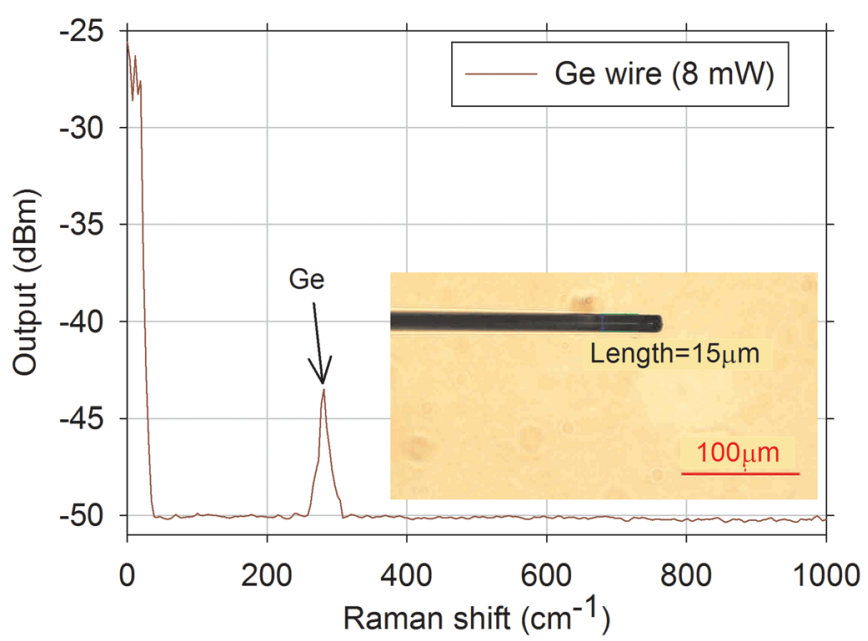

FIG. 4. Raman spectrum of a $15 \mu \mathrm{m}$ Ge wire with a length of $4 \mathrm{~mm}$. Average pump power is $8 \mathrm{~mW}$. Inset: Microscope image of the Ge wire.

optical fiber, along with the output of the Ge wire at $8 \mathrm{~mW}$ only. As expected, the Raman signal increases with increasing pump power. The fiber and the Ge-wire are found to have the same Raman gain at $\lambda \sim 6.8 \mu \mathrm{m}$. The reason for this is that although the borosilicate glass exhibits an estimated optical loss in the order of ten $\mathrm{dB} / \mathrm{mm}$ at $\lambda \sim 5.6 \mu \mathrm{m},{ }^{17}$ the fraction of the propagating fundamental mode in the borosilicate cladding is only $(1-\eta) \sim 10^{-4}$, resulting in an overall negligible linear loss for typical working lengths of few millimeters. The Raman scattering generated in the cladding is detectable because it is coupled into the high refractive index core, where it is guided and collected at the output. The working principle of this experiment is similar to that for attenuated total reflection (ATR) processes commonly used in Fourier transformed infrared (FTIR) spectroscopy.

If the spectra of Fig. 5 are approximated by Lorentzian curves, the spontaneous Raman cross section (fraction of scattered radiation per unit of solid angle per unit length) for the crystalline Germanium core can be estimated as $\mathrm{d} \sigma /$ $\left.\mathrm{d} \Omega\right|_{\mathrm{Ge}}=3.7 \times 10^{-29} \mathrm{~cm}^{2} / \mathrm{sr}$. The stimulated Raman gain coefficient, $g_{s}$, is derived from the well-known equation ${ }^{18}$

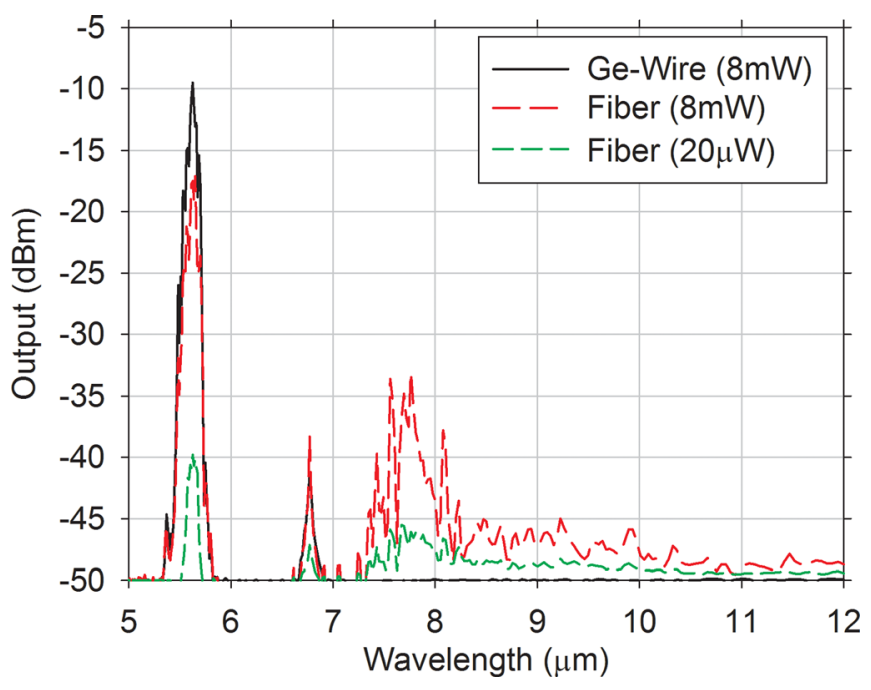

FIG. 5. Raman spectra versus wavelength for different input powers.

$$
g_{s}=\frac{8 \pi c^{2} \omega_{p} \rho}{\hbar \omega_{s}^{4} n^{2}\left(\omega_{s}\right) \Delta \omega} \frac{d \sigma}{d \Omega}
$$

where $c$ is the speed of light in vacuum, $\rho$ is the scatterer density, $\hbar$ is the reduced Planck's constant, $\omega_{p}$ and $\omega_{s}$ are the pump and Raman frequency, $n\left(\omega_{s}\right)$ is the refractive index of the scattering medium at the Raman frequency, and $\Delta \omega$ is the FWHM of the spontaneous Raman line-shape. From Eq. (1), the Raman gain coefficient for Ge is estimated to be $g_{s}$ $\sim 8.6 \times 10^{-12} \mathrm{~m} / \mathrm{W}$.

Comparing the estimated Raman gain coefficient for $\mathrm{Ge}$ with published values is difficult because no data are available in the literature for the spontaneous Raman cross section of germanium. However, it was found in Ref. 13 that $\mathrm{d} \sigma /\left.\mathrm{d} \Omega\right|_{\mathrm{Ge}}$ is 1.25-2 times larger than $\mathrm{d} \sigma /\left.\mathrm{d} \Omega\right|_{\mathrm{Si}}$. The Raman gain coefficient of silicon was found to be of the order of $g_{s(\mathrm{Si})}$ $\sim 7.5 \times 10^{-11} \mathrm{~m} / \mathrm{W}$ (Ref. 19) at $\lambda \sim 1.6 \mu \mathrm{m}$, which is $2.3 \times 10^{3}$ times larger than that of a standard SMF28 silica fiber. As $\Delta \omega_{\mathrm{Si}} \sim 1.2 \Delta \omega_{\mathrm{Ge}}$ (Ref. 13) and Eq. (1) is dependent on $\omega_{\mathrm{s}}{ }^{-4}$, assuming $\mathrm{n}_{\mathrm{Ge}} \sim 4.02, \mathrm{n}_{\mathrm{Si}} \sim 3.42$, and $\mathrm{d} \sigma /\left.\mathrm{d} \Omega\right|_{\mathrm{Ge}}=2$ $\mathrm{d} \sigma /\left.\mathrm{d} \Omega\right|_{\mathrm{Si}}$, then the stimulated gain coefficient for $\mathrm{Ge}$ at $\lambda \sim 5.6 \mu \mathrm{m}$ based on the available data in the literature can be determined as $g_{s(\mathrm{Ge})} \sim 3.05 \times 10^{-12} \mathrm{~m} / \mathrm{W}$, comparable with the estimated value above. Work is presently underway to increase the power coupling between the source and the Ge fiber and thus improve the pumping efficiency of the system.

In conclusion, mid-IR sources that exploit the spontaneous Raman scattering in semiconductor core optical fibers have been demonstrated. Specifically, strong and broad spectra were observed from a $15 \mu \mathrm{m}$ core size glass-clad germanium core fiber with a length of $4 \mathrm{~mm}$ and a germanium wire pumped by a QCL source at $5.62 \mu \mathrm{m}$. Although the QCL pumping source used in the experiments is not low cost, nevertheless the system provides enhanced power output and the pumping efficiency of the system can be enhanced by optimizing both the pumping source and the coupling method. Finally, it is important to point out that this work opens an approach to generate high brightness mid-IR radiation using a Ge fiber. Similarly to the case of high power fiber lasers, low brightness sources can be used to pump fiberized components to produce a high brightness output. This technology can expand the uses of silicon/germanium photonics beyond data communication and into the applications of trace gas sensing, biomedical, and military systems.

The authors would like to thank Dr. X. Feng and Professor J. Zheng for the helpful discussion. P. Wang was funded by the Irish Research Council, co-funded by the EU MarieCurie Actions under FP7, Q. Wu gratefully acknowledges the support of Science Foundation Ireland under Grant Nos. 07/SK/I1200, 11/TIDA/B2051, 07/SK/I1200-STTF11, and 07/SK/I1200-ISTTF11, and G. Brambilla gratefully acknowledges the Royal Society (London) for his research fellowship.

${ }^{1}$ J. Faist, F. Capasso, D. Sivco, C. Sirtori, A. Hutchinson, and A. Cho, Science 264, 553 (1994).

${ }^{2}$ S. Kumar, IEEE J. Sel. Top. Quantum Electron. 17, 38 (2011).

${ }^{3}$ Y. Yao, A. J. Hoffman, and C. F. Gmachl, Nature Photon. 6, 432 (2012).

${ }^{4}$ J. S. Sanghera, L. B. Shaw, and I. D. Aggarwal, IEEE J. Sel. Top. Quantum Electron. 15, 114 (2009). 
${ }^{5}$ Y. J. Ding, IEEE J. Sel. Top. Quantum Electron. 13, 705 (2007).

${ }^{6}$ R. A. Soref, Appl. Opt. 31, 4627 (1992).

${ }^{7}$ M. J. Weber, Handbook of Optical Materials (CRC, 2003), p. 277.

${ }^{8}$ H. E. Bennett, in 18th Annual Symposium on Optical Materials for High Power Lasers (National Institute of Standards and Technology, Boulder, Colorado, 1986), p. 567.

${ }^{9}$ Nature Editorial, Nature Photon. 6, 407 (2012).

${ }^{10}$ R. Camacho-Aguilera, Y. Cai, N. Patel, J. Bessette, M. Romagnoli, L. Kimerling, and J. Michel, Opt. Express 20, 11316 (2012).

${ }^{11}$ S.-L. Cheng, G. Shambat, J. Lu, H.-Y. Yu, K. Saraswat, T. I. Kamins, J. Vuckovic, and Y. Nishi, Appl. Phys. Lett. 98, 211101 (2011).

${ }^{12}$ P. Wang, T. Lee, M. Ding, A. Dhar, T. Hawkins, P. Foy, Y. Semenova, Q. Wu, J. Sahu, G. Farrell, J. Ballato, and G. Brambilla, Opt. Lett. 37, 728 (2012).
${ }^{13}$ J. H. Parker, Jr., D. W. Feldman, and M. Ashkin, Phys. Rev. 155, 712 (1967).

${ }^{14}$ H. Rong, R. Jones, A. Liu, O. Cohen, D. Hak, A. Fang, and M. Pannicia, Nature 433, 725 (2005).

${ }^{15}$ J. Ballato, T. Hawkins, P. Foy, B. Yazgan-Kokuoz, R. Stolen, C. McMillen, N. K. Hon, B. Jalali, and R. Rice, Opt. Express 17, 8029 (2009).

${ }^{16}$ O. N. Koroleva, L. A. Shabunina, and V. N. Bykov, Glass \& Ceram. 67, 340 (2011).

${ }^{17}$ D. G. Drummond, Proc. R. Soc. London, Ser. A 153, 328 (1936).

${ }^{18}$ J. M. Ralston and R. K. Chang, Phys. Rev. B 2, 1858 (1970).

${ }^{19}$ H. Rong, A. Liu, R. Jones, O. Cohen, D. Hak, R. Nicolaescu, A. Fang, and M. Paniccia, Nature 433, 292 (2005). 